\title{
Introduction
}

\section{Intraoperative spinal imaging and navigation}

\author{
Doniel Drazin, M.D., ${ }^{1}$ Terrence T. Kim, M.D., ${ }^{2}$ \\ David W. Polly JR., M.D., ${ }^{3}$ And J. Patrick Johnson, M.D. ${ }^{1,4}$ \\ Departments of ${ }^{1}$ Neurosurgery and ${ }^{2}$ Orthopaedics, Cedars-Sinai \\ Medical Center, Los Angeles, California; ${ }^{3}$ Department of Ortho- \\ paedic Surgery, University of Minnesota, Minneapolis, Minnesota; \\ and ${ }^{4}$ Department of Neurosurgery, University of California-Davis, \\ Sacramento, California
}

Image-guided surgery (IGS) has been evolving since the early 1990s and is now used on a daily basis in the operating theater for spine surgery at many institutions. In the last 5 years, spinal IGS has greatly benefitted from important enhancements including portable intraoperative CT (iCT) coupled with high-speed computerized stereotactic navigation systems and optical-based camera tracking technology.

\section{Historical Perspective}

Cranial stereotaxy was developed by Kirschner in 1933, refined by Lars Leksell in 1949, and translated by Robert Brown and Theodore Roberts in 1979 into the Brown-Roberts-Wells stereotactic system. . $^{21,24,28,35}$ Cranial stereotaxy employed frames that were attached to the skull for numerous surgical intracranial procedures including intraaxial and skull base tumor resection, vascular malformation resection, resection for epilepsy, and ablation and stimulation procedures for Parkinson's disease and other functional disorders. $3,4,11,12$

Today, frame-based technology is used only for some cranial procedures in which the highest possible accuracy is needed. Frame-based cranial stereotaxy led to the development of frameless cranial stereotaxy. Frameless cranial stereotaxy, in turn, led to the development of spinal frameless stereotaxy, now referred to simply as IGS for both cranial and spinal procedures. ${ }^{18,40}$

\section{Frame-Based and Frameless Spinal Stereotaxy Procedures}

For a period of time, frame-based spinal technology was used for the limited applications of stereotactic ra-

Please include this information when citing this paper: DOI: 10.3171/2014.1.FOCUS1425. diosurgery to treat spinal neoplasms. ${ }^{25,32}$ Since the advent of frameless stereotactic radiosurgery procedures, framebased procedures are rarely, if ever, used. The "frameless stereotaxy" that we currently use is now referred to as spinal IGS. This technology utilizes 3D imaging reconstruction produced by iCT scanning, digital optical imaging systems, and high-speed computer processing. Instead of the attached frame previously used, this technology uses only a tracking device attached to the spine to create the 3D computerized tracking environment.

As clinical applications for frameless spinal stereotaxy evolved, they were reported in the literature. In 1991, Nelson and Duwelius reported their novel application of iCT to facilitate sacral fixation. ${ }^{26}$ In 1993 , Brodwater et al. described utilization of the microscope to evaluate lumbar spinal anatomy, creating an interest in the use of IGS for hardware placement. ${ }^{6}$ In 1995, Kalfas and colleagues published their experience with IGS-based placement of pedicle screws in the lumbar spine, in what appears to be the initial application of spinal IGS for hardware placement. ${ }^{17}$ In 1996, Foley and Smith published a paper presenting a broader clinical application of IGS technology to spine surgery procedures. ${ }^{9}$ Following these initial publications, IGS for spinal procedures in various regions of the spinal column were reported by surgeons from across the country. $2,5,15,20,38$

\section{Accuracy}

Since the earliest development of stereotactic procedures, data from preoperative imaging has needed to be entered manually into a computer to achieve "registration" (matching the anatomy with the preoperative imaging features) before a surgical procedure; there has been concern that potential errors could occur and affect patient outcomes as a result of this manual registration method. The accuracy of each phase of a surgical procedure has been studied and reported in the literature. ${ }^{22,25,30,31,36,40} \mathrm{As}$ a result, new testing methods have been developed to assure accuracy, eliminating many of the "registration error" issues that were present prior to the current automatic registration, which is highly accurate..$^{5,13,16,19,20}$

\section{Indications}

Spinal IGS technology has been successfully applied to the craniovertebral junction, atlantoaxial complex, trauma, and tumor resection. It has recently been applied in large-scale use to degenerative and congenital deformi-

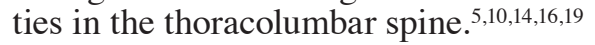




\section{Registration}

The automatic registration process, a major advancement, has allowed IGS technology to be used without necessitating significant surgeon input for this part of the procedure. Previously, the registration process required obtaining a CT scan and either physically or electronically importing the data into the stereotactic IGS workstation so that the spinal anatomy could be matched with the imaging data set. The evolution of IGS registration and the advent of iCT have taken spine IGS from a "procedurally challenged" undertaking to everyday use in the operating room..$^{14,15,33}$

\section{Modern Day}

Spinal surgery has continued to benefit from rapid technological advancements. Pedicle screw fixation has provided rigid fixation to allow biological healing. Screw fixation also allows for the segmental correction of spinal deformity in all planes, but this advance requires precise placement of screws through narrow bony corridors surrounded by high-risk neural, vascular, and visceral structures. Injury to these structures can confer significant morbidity. Advances in computer and imaging technologies have enabled the use of various forms of intraoperative navigation. This navigation allows greater precision of screw placement. While not perfect, it has improved the accuracy of screw placement in many situations, as confirmed by many studies. ${ }^{22,30,39}$

In addition to advancements in imaging and computer-based navigation is the evolution of the mobile CT scanner. While providing excellent imaging resolution and navigation to guide an operation, the mobile CT scanner also permits the surgeon to obtain immediate CT images at the completion of surgery. This allows for immediate intraoperative intervention if necessary before surgical closure. There has been a steady rise in the number of publications addressing navigated spine surgery throughout the spinal axis, innovative applications for ventral approaches and tumor surgery, and novel minimally invasive techniques. ${ }^{8,14-16,22,29,39}$

\section{Radiation Safety}

While many surgeons readily adopt each new development, others are slow to embrace the technology due to concerns such as radiation exposure. From an occupational perspective, numerous reports have documented the harmful effects of radiation exposure to the surgeon and the operative team, and grave concerns exist regarding the stochastic effects of ionizing radiation. ${ }^{22,27}$ Radiation exposure to the patient also needs to be considered. Certainly, a decision between fluoroscopy and CT imaging must be made in the setting of a priori "first, do not harm" threshold for the patient. During the acquisition of iCT images, the operative team steps out of the roomessentially eradicating any occupational radiation exposure. To reduce the amount of radiation exposure directly delivered to the patient, recent low-level radiation-dose protocols for pediatric patients and adjustments in collimation and body habitus have been instituted.

\section{Cost Effectiveness}

There are significant and appropriate debates about the cost effectiveness of the newest technology and the morbidity associated with the additional radiation exposure. It remains unclear as to who will make the decision in the future of whether IGS as a field will continue. Certainly, the assessment of cost effectiveness will likely vary by society's willingness to pay to reduce complications and by the threshold of what conditions are treated versus not treated. Although a handful of studies have looked into CT-IGS in modern health care, there needs to be a more definitive push for future studies. ${ }^{1,734,37}$

\section{In This Issue}

For this issue of Neurosurgical Focus, we invited authors to submit original research or review articles that explored the new advances in the field of image-guided technologies in spine surgery. We were especially interested in articles regarding specific techniques including clinical indications and outcomes, and evaluations of current evidence regarding these technologies. As a result, this issue contains an excellent collection of articles updating the current state of the art in the use of imageguided technology for treating spinal pathology. These articles should further inform spine surgeons about the options and capabilities of this exciting technology. We are pleased to include 10 original manuscripts.

The application of image guidance navigation techniques to address simple or complex pathologies has translated into better outcomes and faster recovery in all areas of the spine. Kim and colleagues demonstrate that minimally invasive surgeries with the use of spinal navigation procedures can be accomplished with a high level of accuracy and safety. In the case of more complex revision surgeries, Hsieh and colleagues show that in a historically challenged procedure, the accuracy of instrumentation placement can approach that seen in index primary cases. Rahmathulla and colleagues review the technical pitfalls and pearls of intraoperative imageguided navigation.

Application of spinal navigation in the cervical spine remains in its infancy. Choudhri and colleagues and Guppy and colleagues take these issues head-on in their reports on navigation techniques to address difficult complex upper cervical pathologies including endoscopic transoral odontoid procedures.

Several reports have looked at spinal navigation in the thoracic spine. The manuscripts in our issue, however, take these ideas to the next level. Jeswani and colleagues focus on the "smallest" of thoracic pedicles measuring $\leq 3 \mathrm{~mm}$, demonstrating that in these difficult cannulations, navigation technology can truly excel. Rivkin and coworkers report on the largest single-institution series to date of navigated thoracic spine instrumentation. They share not only their technical pearls for successful application of image-guided navigation in the thoracic spine but also interestingly describe a "learning curve from the time of their initial use. Johnson and colleagues finish the thoracic spine experience with a report detailing 
a fascinating experience with image navigation in videoassisted thoracic spine surgery.

In the lumbosacral spine, Rodriguez and colleagues report on a novel placement of navigated cortical bone trajectory screws in the previously instrumented patient. Their technical note and revision strategy for adjacentsegment disease offers the spine surgeon yet another option to achieve successful outcomes.

In a final note, Shweikeh and colleagues present us with a comprehensive, up-to-date report on robotics and navigation in spine surgery. They report on the current state of robotic spine surgery including its advantages and disadvantages, discuss how the present limitations may be surmountable in the future, provide a focus for future research, and suggest some ideas for design improvements. (http://thejns.org/doi/abs/10.3171/2014.1.FOCUS1425)

\section{Acknowledgments}

We need to sincerely thank Dr. John Jane Sr. for his thoughtful manuscript reviews. In addition, our sincere appreciation is extended to Ms. Margie Shreve, Assistant to the Editor, for her help in assuring timely reviews and publication.

\section{Disclosure}

Dr. Kim reports being a consultant for DePuy Synthes.

\section{References}

1. Abe Y, Ito M, Abumi K, Kotani Y, Sudo H, Minami A: A novel cost-effective computer-assisted imaging technology for accurate placement of thoracic pedicle screws. Technical note. J Neurosurg Spine 15:479-485, 2011

2. Albert TJ, Klein GR, Vaccaro AR: Image-guided anterior cervical corpectomy. A feasibility study. Spine (Phila Pa 1976) 24:826-830, 1999

3. Apuzzo ML, Chen JC: Stereotaxy, navigation and the temporal concatenation. Stereotact Funct Neurosurg 72:82-88, 1999

4. Barnett GH, Kormos DW, Steiner CP, Weisenberger J: Intraoperative localization using an armless, frameless stereotactic wand. Technical note. J Neurosurg 78:510-514, 1993

5. Bloch O, Holly LT, Park J, Obasi C, Kim K, Johnson JP: Effect of frameless stereotaxy on the accuracy of C1-2 transarticular screw placement. J Neurosurg 95 (1 Suppl):74-79, 2001

6. Brodwater BK, Roberts DW, Nakajima T, Friets EM, Strohbehn JW: Extracranial application of the frameless stereotactic operating microscope: experience with lumbar spine. Neurosurgery 32:209-213, 1993

7. Costa F, Porazzi E, Restelli U, Foglia E, Cardia A, Ortolina A, et al: Economic study: a cost-effectiveness analysis of an intraoperative compared with a pre-operative image guided system in lumbar pedicle screw fixation in patients with degenerative spondylolisthesis. Spine J [epub ahead of print], 2013

8. Drazin D, Liu JC, Acosta FL Jr: CT navigated lateral interbody fusion. J Clin Neurosci 20:1438-1441, 2013

9. Foley KT, Smith MM: Image-guided spine surgery. Neurosurg Clin N Am 7:171-186, 1996

10. Ghostine S, Vaynman S, Schoeb JS, Cambron HO, King WA, Samudrala S, et al: Image-guided thoracoscopic resection of thoracic dumbbell nerve sheath tumors. Neurosurgery 70: 461-468, 2012

11. Golfinos JG, Fitzpatrick BC, Smith LR, Spetzler RF: Clinical use of a frameless stereotactic arm: results of 325 cases. J Neurosurg 83:197-205, 1995
12. Grunert P, Darabi K, Espinosa J, Filippi R: Computer-aided navigation in neurosurgery. Neurosurg Rev 26:73-101, 2003

13. Helm PA, Eckel TS: Accuracy of registration methods in frameless stereotaxis. Comput Aided Surg 3:51-56, 1998

14. Holly LT, Bloch O, Johnson JP: Evaluation of registration techniques for spinal image guidance. J Neurosurg Spine 4: 323-328, 2006

15. Holly LT, Bloch O, Obasi C, Johnson JP: Frameless stereotaxy for anterior spinal procedures. J Neurosurg 95 (2 Suppl): 196-201, 2001

16. Johnson JP, Stokes JK, Oskouian RJ, Choi WW, King WA: Image-guided thoracoscopic spinal surgery: a merging of 2 technologies. Spine (Phila Pa 1796) 30:E572-E578, 2005

17. Kalfas IH, Kormos DW, Murphy MA, McKenzie RL, Barnett GH, Bell GR, et al: Application of frameless stereotaxy to pedicle screw fixation of the spine. J Neurosurg 83:641-647, 1995

18. Kato A, Yoshimine T, Hayakawa T, Tomita Y, Ikeda T, Mitomo M, et al: A frameless, armless navigational system for computer-assisted neurosurgery. Technical note. J Neurosurg 74:845-849, 1991

19. Kim KD, Johnson JP, Bloch O, Masciopinto JE: Computerassisted thoracic pedicle screw placement: an in vitro feasibility study. Spine (Phila Pa 1976) 26:360-364, 2001

20. Kim KD, Johnson JP, Masciopinto JE, Bloch O, Saracen MJ, Villablanca JP: Universal calibration of surgical instruments for spinal stereotaxy. Neurosurgery 44:173-178, 1999

21. Kirschner M: Die Punktionstechnik und die Elektrokoagulation des Ganglion Gasseri. Über gezielte Operationen. Arch Klin Chir 176:581-620, 1933

22. Larson AN, Polly DW Jr, Guidera KJ, Mielke CH, Santos ER, Ledonio CG, et al: The accuracy of navigation and 3D imageguided placement for the placement of pedicle screws in congenital spine deformity. J Pediatr Orthop 32:e23-e29, 2012

23. Lee K, Lee KM, Park MS, Lee B, Kwon DG, Chung CY: Measurements of surgeons' exposure to ionizing radiation dose during intraoperative use of C-arm fluoroscopy. Spine (Phila Pa 1976) 37:1240-1244, 2012

24. Leksell L: A stereotactic apparatus for intracranial surgery. Acta Chir Scand 99:229-233, 1949

25. Medin PM, Solberg TD, De Salles AAF, Cagnon CH, Selch MT, Johnson JP, et al: Investigations of a minimally invasive method for treatment of spinal malignancies with LINAC stereotactic radiation therapy: accuracy and animal studies. Int J Radiat Oncol Biol Phys 52:1111-1122, 2002

26. Nelson DW, Duwelius PJ: CT-guided fixation of sacral fractures and sacroiliac joint disruptions. Radiology 180:527532,1991

27. Rampersaud YR, Foley KT, Shen AC, Williams S, Solomito $\mathrm{M}$ : Radiation exposure to the spine surgeon during fluoroscopically assisted pedicle screw insertion. Spine (Phila Pa 1976) 25:2637-2645, 2000

28. Roberts DW, Strohbehn JW, Hatch JF, Murray W, Kettenberger H: A frameless stereotaxic integration of computerized tomographic imaging and the operating microscope. $\mathbf{J}$ Neurosurg 65:545-549, 1986

29. Sembrano JN, Santos ER, Polly DW Jr: New generation intraoperative three-dimensional imaging (O-arm) in 100 spine surgeries: does it change the surgical procedure? J Clin Neurosci 21:225-231, 2014

30. Sipos EP, Tebo SA, Zinreich SJ, Long DM, Brem H: In vivo accuracy testing and clinical experience with the ISG Viewing Wand. Neurosurgery 39:194-204, 1996

31. Steinmeier R, Rachinger J, Kaus M, Ganslandt O, Huk W, Fahlbusch R: Factors influencing the application accuracy of neuronavigation systems. Stereotact Funct Neurosurg 75:188-202, 2000

32. Takacs II, Hamilton AJ, Lulu B, Fosmire H, Johnson P, Stea $\mathrm{B}$, et al: Frame based stereotactic spinal radiosurgery: experi- 
ence from the first 19 patients treated. Stereotact Funct Neurosurg 73:69, 1999

33. Villalobos H, Germano IM: Clinical evaluation of multimodality registration in frameless stereotaxy. Comput Aided Surg 4: 45-49, 1999

34. Watkins RG, Gupta A, Watkins RG: Cost-effectiveness of image-guided spine surgery. Open Orthop J 4:228-233, 2010

35. Wells TH Jr, Cosman ER, Ball RE: The Brown-Roberts-Wells (BRW) arc: its concept as a spatial navigation system. Appl Neurophysiol 50:127-132, 1987

36. West JB, Fitzpatrick JM, Toms SA, Maurer CR Jr, Maciunas RJ: Fiducial point placement and the accuracy of point-based, rigid body registration. Neurosurgery 48:810-817, 2001

37. Yaszemski MJ, Polly DW, Boden SD, Andersson GB: Technol- ogy assessment: approach and reimbursement. Spine (Phila Pa 1976) 32 (11 Suppl):S39-S43, 2007

38. Youkilis AS, Quint DJ, McGillicuddy JE, Papadopoulos SM: Stereotactic navigation for placement of pedicle screws in the thoracic spine. Neurosurgery 48:771-779, 2001

39. Yson SC, Sembrano JN, Sanders PC, Santos ER, Ledonio CG, Polly DW Jr: Comparison of cranial facet joint violation rates between open and percutaneous pedicle screw placement using intraoperative 3-D CT (O-arm) computer navigation. Spine (Phila Pa 1976) 38:E251-E258, 2013

40. Zinreich SJ, Tebo SA, Long DM, Brem H, Mattox DE, Loury $\mathrm{ME}$, et al: Frameless stereotaxic integration of CT imaging data: accuracy and initial applications. Radiology 188:735742,1993 